\section{DIALÉCTICA GENERAL \\ DE LO \\ ESTÉTICO}

Hermann Güendel A. *

\section{RESUMEN}

La belleza es un requisito que exigimos los hombres para soportar la existencia dentro de la realidad. Esta belleza es condición esencial para poder transformar la existencia en vida, la burda realidad en nuestro mundo. La belleza y lo bello se forjan a través de un magnífico esfuerzo creador, revolucionario en su más profundo sentido. En este ensayo se explora el tema de lo bello y la organización de la realidad en la dirección de hacerla habitable, intentando una explicación del fenómeno estético centrada en el hombre.

\section{Genealogía de lo estético}

El mundo es la creación más elaborada del hombre. A través de siglos de laborioso ingenio, arrojado por su conciencia a la desesperación de

* Licenciado en Filosofía por la UCR. Autor de numerosos artículos y ensayos especializados. Es profesor de la Cátedra de Filosofía de la UNED. una existencia sin sentido dentro de una naturaleza hostil, el hombre se ha levantado como un rebelde que debe reconstituir lo natural que le rodea en un lugar propio. Construye así un mundo habitable como respuesta a la necesidad de sobrevivir en la naturaleza. Ya Hegel señalaba que: "el hombre realiza la transformación de lo externo, sobre lo cual imprime el sello de su ser interno... esto lo hace para anular en el mundo... la dureza extraña" (Hegel, 1983:26). A través de su acción la naturaleza es apropiada y enriquecida por el hombre a tal grado que la hace agradable para habitar en ella.

En medio de la naturaleza que resultó antagónica a la humanidad desde el primer momento, el hombre solo podía actuar sobre ella a través de dos herramientas: una, la percepción inmediata, ${ }^{1}$ y la otra el instinto. Con base en esa acción, nuestra inteligencia nos levantó por encima de la esclavitud a lo inmediato, colocándonos en posición del amo de un mundo que empezábamos a configurar. Tal dominio tiene por condición, desde ayer hasta hoy, una asimilación conceptual de

1. Esta es la interpretación que creo es la más cercana a la intención de Hegel cuando asegura en sus lecciones sobre estética que: "El modo sensible de la conciencia es el más originario", Ibidem, p. 39. 
lo natural. La naturaleza, percibida de modo inmediato como algo objetivamente "acabado", es reconfigurada en conceptos y categorías, para que, finalmente, se organicen estos como visiones de mundo, a través de las cuales el hombre comprende y organiza su acción sobre lo real para dominar la realidad el hombre debe primero, como parte de la práctica que despliega sobre ella, apropiarse de ella conceptualmente, dicho de otro modo, entenderla.

Este entender lo real inició con una "deconstrucción" de lo objetivo, un proceso de experimentación; y no debe estar lejos de la verdad creer que tal proceder debió concluir, en no muy pocos casos, con la muerte de quien experimentaba. Desde esos errores construimos nuestros aciertos, pues con el tiempo la experiencia permitió que nuestro intelecto madurara hasta un primer conocimiento instrumental: la técnica.

La primera percepción de la realidad fue una mera "estética" natural, el "ver" primitivo que abrió la senda de nuestra racionalidad, convirtiendo el instinto en el origen de nuestro entendimiento, un logro que no podemos atribuir al azar; sino a que ya en el hombre más primitivo existía la chispa de la inteligencia. Nuestro intelecto ha crecido a través de la acción de transfor- mar lo natural en mundo. Lo distintivo del hombre en la naturaleza es esta acción revolucionaria, por la cual transforma sin cesar la realidad que lo rodea. El hombre ha logrado subsistir a su propia existencia dándole algún sentido por medio de transformar la naturaleza en el mundo en que vive.

El despliegue del hombre sobre la naturaleza destruyó la simpleza de aquella estética primigenia, y la hace resurgir reconvertida en imposición de una perspectiva específica de aquello que se ha configurado en un lugar agradable para ser habitado, el mundo. Este nuevo "ver" el entorno es a lo que llamo una estética histórica. Se trata, propiamente, de la reconfiguración de la percepción simple de lo natural, en el punto de vista propio de quién se propone a sí mismo como el único señor del mundo que ha creado. Es, por tanto, una "sensibilidad" condicionante de la percepción del mundo. Solo en el terreno de la transformación de la naturaleza en un mundo habitable, nos es posible introducirle belleza. La estética surge de las exigencias de agrado y habitabilidad que nuestra inteligencia define en el despliegue transformador, verdaderamente revolucionario, del hombre sobre lo real. 
Es por ello que lo estético se hace presente en todas las esferas de la actividad humana en su mundo $e x$ illo tempore hasta hoy.

Formando parte de la incluso de la identidad cultural en la que el hombre impone una perspectiva sobre los objetos que constituyen su mundo. En lo estético encontramos el contenido humano que hace habitable al mundo, pues lo hace de lo real algo agradable.

La acción de la inteligencia en la estética histórica del mundo no se agota con deconstruir lo real para codificarlo, sino que, de modo permanente, reconfigura la agradabilidad para materializarla como cuali$\mathrm{dad}^{2}$ en la constitución del objeto que llamamos bello; ya decía Hegel

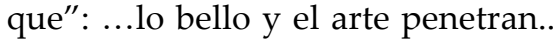
como un genio amigo a través de todos los aspectos de la vida y adornan brillantemente todas las circunstancias...mitigan.. la seriedad de las relaciones y complicaciones de la realidad" (Hegel, 1983:42). En la materialización de la estética, la inteligencia humana se manifiesta como imaginación que permite constituir la belleza en el mundo.

2. En este sentido coincido plenamente con A. Bretón sobre el valor de la belleza y la chispa que ella produce en el mundo, véase para ello el primer manifiesto del surrealismo, p. 59.

\section{La belleza natural}

La belleza no es una propiedad de la naturaleza. El hombre plasma lo bello en los objetos del mundo porque lo encuentra en la naturaleza. Al contrario, en ella solo encuentra la grosera antagonía entre el existir y la muerte. Lo bello natural no es, propiamente dicho, un componente de la naturaleza, más bien es una simple perspectiva humana, fundada en la impresionabilidad de un hombre ante las proporciones que observa, desde un ángulo de visión específico, en la naturaleza colocada frente a sí como un paisaje. No hay una belleza natural, sino tan solo una perspectiva que fija en un instante la espacialidad de la naturaleza, la cual desde otro ángulo puede no tener valor $\mathrm{y}$, más aún, ser horrorosa.

La posibilidad de un juicio sobre lo bello natural valedero de modo universal, se reduce a una pura coincidencia casual en el espacio y el tiempo de observación del entorno. Fuera de ella, la perspectiva se rompe, pues en la naturaleza, a diferencia del mundo, no hay belleza, sino solamente utilidad.

La percepción de lo que mal llamamos belleza natural, como una puesta de sol, no es jamás un acto desinteresado, sino que más bien es un profundo acto de egoísmo en el 
que el hombre se enseñorea, desde su poder, de la naturaleza que ha reconfigurado como su mundo. El hombre impone perspectivas de percepción a la realidad. En ello solo podemos reconocer un acto arrogante, el de otorgarse el derecho de ser "la medida de todas las cosas", y por tanto ser el único propietario del mundo que ha creado a imagen y semejanza de su voluntad que responde solamente a aquello que resulta necesario para sobrevivir Por ello esta imposición de una estética histórica, o perspectiva de la belleza en el mundo, no es más que un acto de poderío. A través de este podemos evidenciar la más profunda reorganización de la naturaleza en un mundo agradable que dé sentido a nuestra existencia. En efecto, a lo largo de los siglos, se ha logrado construir un mundo, pero su innegable fealdad capitalista actual, su brutal carencia y clasismo, nos obliga a retransformarlo, de nuevo, en un lugar agradable.

La percepción de la "belleza natural" se realiza propiamente, entonces, solo desde una posición cultural. Una relación entre un yo específico con una perspectiva específica, en la cual se destaca un ángulo, reduciendo así lo natural a su posición en el mundo, sin reconocer como algo fundamental su total arbitrariedad. Desde que el hombre se impuso, por medio de su inteligencia, a la naturaleza dándole la forma del mundo, perdió la capacidad de verla con la ingenuidad que ella le exige a sus esclavos. El hombre contempla lo natural en su mundo como parte de este, desde la posición de dueño y espectador. La estetización de la naturaleza es así la imposición de un contenido humano y una cualidad de agrado a algo que no tiene que poseerlo; debo hacer mía aquella idea de Hegel: "...lo bello natural aparece solo como reflejo de la belleza que pertenece al espíritu" (Hegel, 1983, t. 2:40).

De modo material, esa imposición de contenido es dada, o bien desde una corriente estética madura, o bien desde una sensibilidad estética, es decir, desde una intuición de belleza que no genera discurso. Así pues, solo podemos juzgar lo bello desde una estética dentro de la cual se ha constituido como objeto de este mundo.

\section{El juicio sobre la belleza}

El juicio sobre lo bello resulta ser un acto de extraordinaria complejidad.

Si bien lo vivimos con la despreocupada apariencia del fruto de mi gusto más íntimo, nada resulta más lejano a la verdad que creer que el juicio estético sea incondicionado $\mathrm{y}$ desinteresado, como lo pretendió 
$K{ }^{3}{ }^{3}$ en su época. Por el contrario, en el juicio estético que es, por demás decir, el primer modo de aproximación al objeto bello que poseemos, intervienen una gran cantidad de elementos, y de relaciones antropológicas, ontológicas, y epistemológicas, que solo la filosofía puede elucidar. Bien señaló Hegel que: “el proceso de explicación filosófico consiste, en una parte, en la profundización del contenido espiritual, por otro, en la prueba de que el arte solo busca su contenido adecuado, luego lo encuentra, y por fin lo supera" (Hegel, 1983, t. 8:34).

La estética histórica consiste en la sensibilidad de la época hacia la belleza. Su origen concreto se encuentra en la actividad transformadora de la realidad natural, en el mundo que habitamos, y en la permanente reconstrucción de este. Por ello, la estética del mundo afecta todo lo que dentro de él se afirma como real $\mathrm{y}$, sin duda, al hombre mismo, pues exigimos para vivir con cierta comodidad, junto a un mundo agradable, el que los otros sean igual-

3. En sus lecciones sobre estética Hegel destroza la estética kantiana por medio de tres grandes críticas que suponen un agudo reconocimiento de la multidimensionalidad del hombre frente al simplista concepto de hombre presente en Kant. mente agradables para poder convivir con ellos. ${ }^{4}$

La belleza en la apariencia del ser humano es el único modo a través del cual podemos obviar el terrible desagrado que nos produce los múltiples rostros que todos poseemos y que nos convierten en hipócritas aún con nosotros mismos.

No hay frontera que la belleza no pueda traspasar, ni lugar en el que no pueda residir, así sea ese una cárcel, o una tumba. El condicionamiento estético cubre desde la esfera de lo sublime hasta lo prosaico. Vemos, por ello, que en el mundo la belleza se manifiesta tanto en el arte, como en la moda, en el magnífico mural, o en el automóvil. Esto nos coloca en posición de poder definir la belleza en un momento histórico y, dentro de los límites de una sensibilidad estética, de modo que sea efectiva en la práctica. La belleza es una perspectiva condicionada por una estética.

El juicio de gusto enuncia la cualidad estética del objeto artístico en el contexto histórico de las relaciones generales de la humanidad con su mundo. Esas relaciones, a su vez,

4. Hegel hace un aguda observación cuando dice: “..el hombre.. tiene que adornarse a sí mismo y al ambiente en el que vive...", Estética, tomo 2, p. 239. 
constituyen el espacio de efectividad para que la imaginación logre constituir una sensibilidad de la época hacia lo bello, que es en realidad lo que hace agradable el lugar que habitamos. Lo bello es concreto, una intuición histórica particular. Por ello, resulta materializable como propiedad de un objeto que lo expone sin necesidad de discurso.

La estética histórica es construida por la imaginación a través de una lógica particular. Lo bello se constituye dentro del mundo como objeto, porque la imaginación configura una intuición que no alcanza a constituir el rango del discurso, o sea una sensibilidad, en práctica concreta sobre lo real.

El gusto estético común es fruto de la identidad estética entre espectadores y artista, sobre una propuesta de belleza materializada en una obra particular.

\section{La percepción de lo bello en el mundo}

La estética es la percepción de la belleza en el mundo. Por ello, marca un enseñoramiento sobre el mundo, vivido por cada cual como una percepción específica dirigida primero hacia los objetos particulares, que se desarrolla después, como efecto de la acción de la inteligencia, hasta to- mar cuerpo en una corriente estética; esto es una sensibilidad que alcanza el rango de discurso y, propone entonces cánones.

La estética histórica contiene, sin duda, una inteligibilidad general de la acción del hombre sobre lo real, ya sea la naturaleza o el mundo. La estetización de lo real asume así un significado particular como huella de la humanidad, y es, a la vez, la razón por la cual coinciden el artista y el público como espectadores de la misma belleza. El artista al materializar lo bello, y el público al reconocerlo, se "mueve" dentro de una misma sensibilidad estética, que les resulta común gracias a la actividad del ser humano genérico que cada uno expone particularmente como una relación propia de la identidad social de múltiples individuos, es decir, una identidad cultural. Esa identidad estética cultural condiciona el juicio del público y la materialización de la belleza dentro del proyecto del artista.

Ahora bien, la posibilidad de constituir una identidad cultural que sea el espacio de efectividad de una comunidad de juicios estéticos, solo se da por medio de la fuerza vital humana desplegada siempre en una situación histórica. Retomemos aquí una atinada observación de Bretón: 
“...el problema de la acción social es únicamente (ser) una de las formas de un problema más general, que no es otro que el de la expresión humana en todas sus formas" (1969:195).

La vitalidad del género humano es lo que mueve la historia en sus formas particulares, y es lo que convierte al hombre en su propio producto. Así, la estética de la belleza en el mundo se constituye, por propio derecho, en parte fundamental del esfuerzo humano de forjar una consciencia de su propia historicidad, su identidad concreta como pueblo y finalmente como estado nacional. La esteticidad de un pueblo tiene protagonismo en la constitución de su identidad cultural.

En su creación, el artista encierra la complejidad de la acción humana sobre la realidad, viviéndola, en su individualidad, como impulso creativo. ${ }^{5}$ La vitalidad de la fuerza revolucionaria humana es el más profundo origen de ese impulso que lleva al artista a dar cuerpo, en una obra de arte, a su mundo subjetivo.

5. En su "Estética", Hegel propone que "...el artista debe comportarse creadoramente y en su propia fantasía...formar y configurar enteramente y de un golpe el significado que lo anima", tomo 2, p. 130.
El artista materializa la belleza cuando plasma en el objeto una sensibilidad o corriente estética. Esto lo puede hacer al particularizar, en su acto de creación, la misma fuerza con la que la humanidad transforma la naturaleza en mundo, y hoy, el viejo mundo un mundo nuevo. La creación artística refleja el movimiento que transforma las fronteras de este mundo. La sensibilidad estética es, de este modo, la armazón interna del arte en general. A través de ella, cada obra particular posee una rica coherencia que la configura como una totalidad inseparable, que nos impide dar prioridad ya a la forma, o ya al contenido. La belleza del objeto artístico no reside ni en la forma, como pretendió Kant, ni en la adecuación entre la forma y el contenido, como creía Hegel, sino en la estética que materializa.

\section{Sensibilidades y corrientes estéticas}

Ya sea que nos enfrentemos a una estética específica como sensibilidad o, como corriente, lo esencial es que ella es vertida en la obra para ser gozada. El sentido propio del objeto de arte, según su estética, radica en ser observado, como escribía ya Hegel: “...lo principal es y sigue siendo la comprensión inmediata" (Hegel, 1983, t. 8:259). 
La percepción de la belleza del objeto artístico es, realmente, un reconocimiento de lo bello condicionado por una estética, por ello, antes de definir la belleza, el hombre la disfruta. La belleza se reconoce como cualidad de lo real, solo desde un momento estético específico. Estamos pues ante una historicidad que es plasmada por el artista en su obra y que el público reconoce, ya sea a través de su vivo esplendor, o de la gris culturización producto de la "educación del gusto" a través de la formación académica.

En la historia no ha existido una única definición de lo bello, sino múltiples concepciones de belleza, tantas como situaciones diversas, abiertas por la práctica transformadora, que la imaginación ha logrado convertir en sensibilidades. Las sensibilidades estéticas son profundamente humanistas, pues denuncian al hombre como centro de su mundo. Su contenido no tiene nacionalidades ya que está determinado por un aspecto del género: la fuerza revolucionaria de la humanidad en la realidad.

Por ello, las sensibilidades estéticas pueden ser expresadas por cualquier artista alrededor del mundo; sin embargo, su nacimiento siempre tendrá un matiz geográfico, pues toda sensibilidad siempre es fruto de la imaginación de un sujeto humano concreto.

En la sociedad clasista, este ser humano concreto existe enajenado de sí mismo, deja de ser hombre para ser sujeto de clase, viendo el mundo desde lo que su socialización le urge pensar, actuar y vivir. Por ello, es imposible creer que en esta sociedad capitalista carencial pueda existir una única valoración estética de aquello que llamamos bello. Por el contrario, toda estética depende de la especificidad de la práctica material humana concreta, dentro de una clase social. En esta sociedad de profundas desigualdades no puede existir un espacio común que permita una matriz única de percepción y creatividad estética; sino por el contrario, históricamente se constituyen múltiples matrices desde las que el hombre transforma el mundo o, al menos, salta hacia su mundo inmediato. No puede existir, entonces, una estética general y común hacia la belleza, no porque seamos distintos, sino porque las situaciones materiales son distintas, para distintos hombres, en el seno de una misma sociedad.

Las diversas corrientes, y sensibilidades estéticas que en una sociedad clasista pueden surgir, se organizan históricamente de dos modos: o co- 
mo la corriente dominante, o como las corrientes alternativas. Cada una de ellas posee su espacio de efectividad en las relaciones de producción y consumo del arte en la sociedad capitalista. Es innegable, si nos aproximamos críticamente a la sensibilidad estética dominante en el capitalismo, que se trata esencialmente de una estética fetichista. El arte no es apreciado en su dimensión significativamente humana, o sea la de configurar en algo agradable el mundo que se construye, sino que se le asume desde una posición de objeto de interés para el mercado. La estética fetiche reduce la belleza a una pura formalidad vendible. Esto ha llevado al arte hasta un punto de crisis, en el que pierde la posibilidad de constituirse en un espacio efectivo de comunicación explícita de un mensaje intencional del artista, no es que el artista abandone la urgencia de decir algo, sino que lo que dice no es entendido, porque a nadie le importa.

El arte actual ha sido reducido a un mero objeto, una artesanía cuyo valor está en lucirlo y venderlo por millones de dólares. El arte es, en el capitalismo, solo una buena inversión.

\section{Lo grotesco}

\section{en la estética actual}

Al ser reducido a la burda y grosera dimensión de un gran espectáculo, el arte ha perdido gran parte de su verdadero valor humanista. Por ello, ha de celebrase la reaparición, en el mejor momento, de la rebeldía del hombre. La gestación, dentro del arte actual, de un nuevo espacio de acción creativa y revolucionaria, se trata de una estética alternativa: la de lo grotesco.

A mi juicio, este tipo de estética en el arte consiste en la reaparición del paganismo medieval a finales del siglo veinte, y en este sentido debe ser entendido como un proceso de disolución de la estética fetichista dominante, propio de una reacción de inconformidad del hombre con el mundo que ha construido. Lo grotesco abre un espacio de cuestionamiento para lo dominante, pues lo disuelve sin que se pueda tener hoy claro cuáles serán sus alcances. Lo único que se puede concluir de esto es que toda disolución de una estética dominante aparece, en la historia, dentro de lo contracultural. ${ }^{6}$

6. $\quad$ Escribía Bretón en sus manifiestos: “El surrealismo pretendía ante todo provocar, en lo intelectual y lo moral una crisis de conciencia del tipo más general y grave posible." p. 162. 
Así entendido, lo grotesco se hace significativo del fin de esta crisis fetichista que la estética capitalista ha engendrado. No cabe la menor duda de que la estética fetichista fue desarrollada intencionalmente dentro de un proyecto de intereses en la sociedad capitalista, y que ella pasa directamente a formar parte de la cultura de la sociedad actual a través de la educación, base real de lo que es llamado juicio erudito sobre el arte o crítica de arte. Creo sinceramente que el juicio erudito es simplemente una vulgar valoración ideológica del arte, pues el reconocimiento de una materialización exitosa de lo bello en una obra de arte solo posee sentido si se da por medio del juicio espontáneo del público; no en balde Hegel señalaba que "el arte no es para un pequeño círculo, los menos, los cultos, sino para la nación en su conjunto.. la obra de arte y su goce no existen para el conocedor y los sabios, sino para el público, y los críticos se equivocan al adjudicarse tal privilegio..." (Hegel, 1983, t. 2: 258 y 263). Lo bello no requiere de argumentos para ser real, se le reconoce tal condición con tan solo del juicio espontáneo de quien lo mira.

La crítica erudita petrifica la vida del arte y de la estética que este materializa. Su verdadera razón de ser no se encuentra en la educación del gusto, sino en las particularidades de los proyectos e intereses de poder de aquellos que dominan. A través de la educación pública se deforma a nuestros jóvenes al grado de poder percibir la belleza en el arte solo desde la sensibilidad estética dominante. Se les coacciona hasta el punto de juzgar, como bella, una obra que no responde a su sensibilidad y que, no en pocos casos, se opone a su juvenil gusto. En la sociedad clasista, la cultura es la formación ideológica intencional de la identidad cultural de un pueblo, en la que él es el gran actor ausente.

\section{Dialéctica particular de lo estético en el arte}

El arte, al materializar con la mayor plenitud los alcances de una estética, es una transformación alegórica de la realidad. Su función más significativa y humana es el agregar belleza al mundo. En la creación artística, la fuerza revolucionaria de la humanidad precipita la razón a la acción, logrando, por medio de la imaginación, una objetividad enriquecedora del mundo. El arte no es simplemente, como lo propuso $\mathrm{He}$ gel (1983, t. 5:273), su maestría técnica, pero sin duda este requiere de la técnica para que el genio artístico logre plasmar objetivamente una sensibilidad hacia la belleza. La técnica es algo esencial para la madu- 
ración del talento del artista, pero para el arte lo esencial se encuentra en el modo de transformar.

La obra de arte no es un universo abierto a múltiples juicios. El "universo" de la obra se cierra con la última pincelada del artista, o la última escena del drama; por ello la obra de arte no tiene más que un contenido, y no puede decir algo distinto, en diferentes épocas, a diferentes hombres. Detrás de las múltiples interpretaciones que puedan hacerse de una obra, a lo largo de los años, se encuentra tan solo la necesidad humana de corregir y agregar juicios, no en función de la obra, sino simplemente de la necesidad de comunicarse con otros. El ser de la obra está en su totalidad estética, estructurada por medio de un acto de creatividad. No puede escindirse un elemento sin destruir el todo, no puede priorizarse la técnica, pues, a pesar de ella, muchos intentos alcanzan solo a ser burdas artesanías y no bellas artes. El arte surge en el mundo como el fruto magnífico de una inteligencia que imagina.

Es ella la que configura en sensibilidad la actividad revolucionaria del hombre. Es ella la que impone el sello de la apropiación de la realidad, por medio de la transformación de la naturaleza, y la hace algo agradable.

\section{La imaginación}

Entre la imaginación y la realidad constituida por el hombre existe una íntima relación: ambas son mutuamente significativas, pues, de un lado la realidad no puede ser transformada sin imaginación, y del otro, la imaginación no puede prescindir de contenidos materiales. Sin embargo, la imaginación no está sometida al ordenamiento del mundo, sin que por ello se le oponga. En términos estrictos, la imaginación no puede prescindir de las relaciones de ordenamiento de lo real que se han establecido por medio de una visión de mundo, sino que más bien las supone como fundamento de una imaginería. Por ello, la imaginación puede potenciar la realidad hasta la ficción, instaurando de tal modo un verdadero acto premonitorio del tiempo.

Sin embargo, la imaginación responde a una lógica que le es propia, una que no sigue las reglas de lo formal, ni de lo demente, sino más bien de lo posible. Las fronteras de la imaginación van más allá de la racionalidad formal, permitiéndole al hombre reconocer la libertad en su ser. La imaginación es, de hecho, una racionalidad distinta poseedora de una lógica especial que puede llevar la creatividad hasta la oposición con lo constituido. La lógica de las visiones de mundo es una lógica 
de lo constituido, la lógica de la imaginación es una lógica de lo posible. Mientras que la lógica de lo constituido responde a la objetividad de las relaciones de ordenación del mundo, y por medio de ella el hombre desestructura, conceptualiza, y asimila lo real, la lógica de lo posible, en cambio, responde a la transformación revolucionaria de la realidad mediante la negación de lo constituido.

La imaginación no es una cualidad humana opuesta a la razón, sino que, por el contrario, es la razón misma desbocada en voluntad de transformar, y no puede seguir siendo reducida al grosero rango de la loca de la casa. En cada obra artística se manifiesta la inteligencia que imagina; por ello, la imaginación artística alcanza a crear sonido, o imagen en un todo con sentido en sí mismo, a través de la razón.

La obra de arte, por su sola existencia, expresa un contenido que puede ir más allá de la conciencia del artista. En cada manifestación de las bellas artes está contenida la fuerza revolucionaria del ser humano en una dimensión concreta. Habrá que atribuirle a la genialidad particular de un artista que, en una obra, logre condensar la plenitud del sentido que intentaba expresar, pero es algo distinto que ese conte- nido intencional sea comprendido, pues el arte hoy no es un buen medio de comunicación, ya que es tan solo concebido como un fetiche económico.

El arte se origina, dentro de la transformación de la naturaleza, en un lugar habitable, como una esfera particular de la práctica, la de la objetivación de la belleza. Este proceder manifiesta un acto de apropiación de lo natural, cuya primera forma fue la arcaica concepción mágico-religiosa de lo real. Por ello, las primeras manifestaciones de la actividad artística surgen en el contexto de la visión mágico-religiosa del mundo constituido. En este momento, el arte fue sin duda un lenguaje simbólico, y en cuanto tal, contuvo la expresión más acabada de belleza que nuestros ancestros pudieron engendrar.

Cada época de la historia tiene un arte que se convierte en la máxima expresión de la belleza y la actividad creadora. Tal arte por excelencia sería aquel en el que se concreta la sensibilidad dominante como un arte superior ${ }^{7}$ y sintético. Para el final de este siglo, ese arte fue el cine.

\footnotetext{
7. Hegel creía en un arte superior, aquel que se apropiaba de la representación del espíritu, véase "Estética", tomo 2, p. 126.
} 


\section{El artista}

Más que movido por la necesidad de expresar su visión del mundo, el artista crea movido por una necesidad de transformar una realidad inmediata. Para ello le impone el sello de su subjetividad creadora, a través de la cual apropia la realidad transformada como su obra. El hacer artístico es una forma de la apropiación subjetiva de la transformación de realidad natural e histórica.

La función más propia del arte consiste en hacer del mundo un lugar agradable para habitarlo, el artista no tiene que ir más allá de eso. En el arte se demuestra, de modo latente, la gestación del hombre en su historia, el paso del hombre desde la dependencia de la naturaleza hasta su pleno dominio. Por ello, el más alto valor cultural del arte se resume en ser un vehículo de reencuentro del hombre con su historicidad revolucionaria, transformadora, constituyente del mundo.

El arte existe más allá de las fronteras de un estado, es un producto universal del hombre. Para el genio la visión de mundo dominante en su sociedad es solo un espacio que no encierra sus posibilidades creativas. Frente al genio, un simple artista es esclavo del mundo que habita, y no un revolucionario de él. Mientras que para un simple artista o un burdo artesano, la visión de mundo dominante se convierte en un fin, para un gran artista, ella resulta exterior e incómoda a tal grado que debe levantarse frente a su época estética, no teniendo otra posibilidad que ser un revolucionario que juega con una estética hasta hacerla decaer, o bien, huir frustrado al exilio voluntario. Sin embargo, aún cuando logre liberarse de la mediocridad del medio, este triunfo se convertirá al final en una derrota, pues el arte no es libre, sino esclavo de una estética.

En su dialéctica, el arte se libera de la estética dominante por medio del artista de genio, para caer luego esclavo de su propio acto de liberación. Este es el triste momento en el que la iniciativa rebelde se constituye en corriente estética dominante. El arte, como la humanidad, tiene acceso a la libertad sólo en breves momentos, mismos que, luego, se vuelven en su contra como tiranos que de nuevo debe derrotar.

En el arte, al lado de la estética, se encuentra la técnica que permite fijar toda la fuerza de la racionalidad imaginativa y creativa del artista en un objeto concreto. Se pensaría que la técnica posibilita libertad al artista. Sin embargo, a través de la técnica, el artista se encuentra prisionero de las formas que la naturaleza 
y el mundo le han demostrado como posibles. Por efecto de la técnica la obra siempre conserva las relaciones formales de lo real para su manifestación como objeto artístico. Esto se debe a que el origen de la técnica artística se encuentra en la codificación e instrumentalización de la naturaleza en elementos utilizables. El hombre descompone su alrededor en particularidades instrumentalizables ; así, por ejemplo, el cielo o el árbol son de-construidos y codificados como color, textura, y dimensión. El artista, como hombre, juega con el mundo y la naturaleza sin abandonarlas.

La imaginación interviene en la técnica colocando al hombre en posición de aprehensión de su realidad; por ello, la imaginación posibilita el conocimiento técnico. Es la técnica la que permite que el arte sea una forma de conocimiento. La manifestación más clara de esto la encontramos en el lenguaje poético, que le permite al artista alcanzar niveles intuitivos de verdad, en una dimensión que la razón, en su pesado discurso, ni siquiera sugiere.

En el arte, la imaginación tiene su más alto valor como instrumento de conformación de conocimiento. Por medio de ella, el artista desarrolla apriori una concepción creativa de su obra particular, como lo hacemos todos cuando antes de iniciar una tarea, la planificamos en nuestra mente.

La creatividad artística es un impulso racional, cuyo origen se encuentra en la fuerza genérica particularizada en un hombre colocado frente a la realidad como un ser inconforme siempre con lo que vive y crea. Esta síntesis entre el hombre, el género y lo real, es el verdadero espacio de efectividad de la creatividad artística, pues es ahí en donde se da la transformación particular de lo real.

Ahora bien, la imaginación puede divorciar al artista de la especificidad de su época gracias a la fuerza vital de la humanidad que se manifiesta en él, colocando entonces al genio en una situación sui generis a la cual solo las generaciones del futuro tendrán la capacidad estética de penetrar, ya para reconocer su genialidad o condenarla como una mala broma de la imaginación. La imaginación tiene la capacidad de desarrollar en la subjetividad del artista una subjetividad mayor, la de la actividad histórica, potenciando lo real en su posibilidad, pero no en su necesidad. Esta es la razón por la cual el artista puede ir más allá de su tiempo, pero nadie puede saber si lo ha hecho por genialidad o por simple estupidez, pues la 
imaginación permite ambos extremos, llevando así a muchos artistas al fracaso.

El potenciar en su posibilidad es una capacidad de la imaginación que ha permitido el surgimiento de un arte de ficción; pero la ficción no es el desarrollo de la realidad en la dimensión necesaria; por ello hoy nos causa en ciertas ocasiones, risa aquellas ficciones que sobre el fin de siglo se hicieron en sus principios $y$, en otras, asombro aquellas ficciones que fueron espejo premonitorio de nuestro tiempo cuando este aún no se había dado. Esto es explicable al fin porque la relación epistemológica entre el ser y el pensar no es refleja ni autónoma, sino más bien una mediación histórico-cultural entre el presente y hombre. La imaginación del artista juega a tal grado con estéticas y técnicas, con la realidad y la posibilidad, que se salta su tiempo, con mayor o menor éxito. En este juego, la creatividad termina llevando a caducidad no solo a una sensibilidad o corriente, sino a todo un arte superior, el que expresaba, mejor que ninguno, la estética de su época. Las disoluciones de las sensibilidades estéticas pueden, por tanto, ser tanto accidentales como intencionales.

Este juego del artista con materiales proyectos da al arte una aspiración de libertad, un acto de rebeldía que le aproxima a una liberación, pero la libertad es solo una quimera. El libre juego del artista libera en efecto su creatividad, sin percibir, en este juego, que la libertad esclaviza. El artista forja una nueva sensibilidad estética a través de su imaginación que, convertida en dominante, niega la creatividad por medio de criterios o cánones. Su acto de liberación es solo un acontecimiento que redundará en su negación cuando decae en modo. Por medio de su imaginación el artista forja libremente la cadena que lo esclaviza. Esa cadena es su propia sensibilidad o corriente estética. La única libertad del hombre consiste en construir su libertad y, el precio que paga por hacerlo es su total pérdida. La libertad es nuestra más pesada cadena.

Una nueva sensibilidad estética siempre se rebelará contra aquella dominante que ha petrificado la creatividad al dictar cánones, ya que es necesario destruir para poder crear. En este movimiento liberador de una estética dominante, el arte puede ser llevado más allá de la belleza, perdiendo así su función distintiva en el mundo; deja de ser arte. En este momento de disolución, el arte es simplemente movimiento de liberación que puede asumir formas diversas, y caer, co- 
mo lo hace hoy, en lo grotesco como estética alternativa. Lo grotesco en el arte no es reconocible como arte bello, no aporta belleza, sino que la disuelve. En ello está su significado. Lo grotesco actual es manifestación contracultural de una reacción contra la sensibilidad estética dominante en el capitalismo, y por supuesto contra la existencia misma del hombre en el mundo capitalista. No podemos creer que esta contraculturalidad madure, en su momento, en una transformación de la sociedad. Esto es imposible, porque el arte se constituye en la esfera de las sensibilidades hacia la belleza, que es lo máximo que puede aportar a la imaginación en esta esfera a través de su lógica de lo posible, y no en la de las visiones de mundo que generan prácticas políticas.

Ahora bien, como una estética alternativa no constituye una visión de mundo, su carácter alternativo puede ser asimilado por la sociedad capitalista y sus intereses, convirtiéndose en un excelente negocio como lo es, de hecho, todo el género de lo grotesco. Un momento de disolución de una estética dominante no coincide, por desgracia, con un momento de disolución de la sociedad en la que es dominante.

En el mundo actual, la actividad artística se debate continuamente en- tre el cambio y el estancamiento, entre el esfuerzo irreverente de proponer la novedad estética genial, o simplemente petrificarse en lo constituido como dominante para, de este modo, no morir de hambre o ser censurado por un dictador. Por ello, el artista de genio será siempre un subversivo a nombre de la humanidad.

Lo único que puede rescatar al artista de la mediocridad del medio en el que vive, es el juicio del público, pero este juicio puede ser más bien el epitafio del artista, pues estará siempre presente la posibilidad de que el juicio del público, sobre la belleza del objeto se dirija a una expresión artística fuera de un momento estético-histórico. Esto solo puede ser el resultado de la culturización de una estética dominante, al formar parte del currículum educativo. Es de este modo como la estética fetichista en el capitalismo prefigura a todos los hombres como compradores de arte, sin importar que la obra como tal sea de su agrado.

El público consume, por así decirlo, a la obra de arte como una totalidad penetrada por múltiples intereses, convirtiendo así al arte en la actividad más interesada que puede suponerse. El consumo actual del arte es fetichista, se mueve en el terre- 
no de la falsa valoración. Esta es la base material que sustenta la ideologización de un concepto de arte y de una estética como lo hizo Kant en su época.

En cualquier sentido que se le aborde, la sensibilidad estética es la única mediación real que existe en la relación entre el público, el artista y la obra.

\section{Las bellas artes}

La matriz real de todas las formas de arte se encuentra en la capacidad de la razón humana de insertarse creadoramente sobre la realidad. Es en la acción revolucionaria del hombre que nuestra inteligencia ha separado lo real engendrado, conceptos y distinciones de color, el material, el sonido, etc. Por ello, cada arte posee una propiedad específica dentro de la cual juega el artista. La pintura tiene su propiedad especifica en el tratamiento del color y la imagen; a su lado, el tratamiento de la palabra constituye la poesía; el uso del volumen y la forma son la propiedad de la escultura; la música se levanta frente a las demás artes por medio del sonido y la fuerza en sus combinaciones; la danza irrumpe por medio del movimiento; y el teatro por el tratamiento del discurso y el escenario. Solo hay un arte donde las propiedades de las otras bellas artes confluyen: el cine, arte por excelencia del siglo veinte, cuya especificidad lo constituye fluidez continua en el movimiento de la imagen fotografiada.

El protagonismo de la inteligencia que imagina en el arte se inicia en la misma confrontación asimiladora con la naturaleza que genera la técnica, y configura las sensibilidades estéticas, y alcanza plenitud en la constitución del proyecto del artista y la materialización de una estética.

Cada imagen artística representa, en una alegoría particular, el entorno general transformado por la actividad esencial humana. En cada obra de arte hay una particularidad material abierta a una universalidad: la fuerza transformadora de lo natural en nuestro mundo.

El arte, moviéndose entre la esclavitud y la liberación, requiere de técnica madura y originalidad para materializar la belleza que una sensibilidad estética define. Es por ello que los opuestos tienen en él un reino común. El arte es una región de equilibrio que se constituye por la síntesis de múltiples contradicciones.

Lo que convierte a productos específicos del actuar del hombre en arte, no es su técnica, sino más bien la 
actividad creativa que el hombre despliega dentro de las propiedades específicas de cada arte en particular. No todo acto de transformación de lo real puede ser arte, pero sí todo puede ser afectado por una estética, pues todo puede ser objeto de la actividad del hombre.

Si el arte posee tal excelencia particularizada, cabe aquí considerar su relación con la artesanía que se ha desarrollado dentro de él. En mi opinión, la artesanía ${ }^{8}$ es solo un arte menor, que cumple también, a su modo, la función de brindar agrado, pero con un alcance paupérrimo, que es el de solamente adornar. La artesanía es, en tal sentido, un arte alienado o arte para la inmediatez.

La frontera que la separa del arte es la originalidad unívoca del objeto bello. El artesano reproduce la originalidad hasta volverla anónima, y el creador desaparece detrás del objeto, no se trasluce en él como lo hace en la obra de arte. La obra de artesanía, por ser pura técnica, va más allá de su creador. El objeto se separa de su creador, lo vuelve así inmediatez valorada solo en función de adornar mi hogar. Como vulgar ar-

8. Hegel se refiere a este tema bajo el concepto de manera, que es en realidad un hábito repetitivo, "Estética", tomo 2, p. 283. te alienado lo importante en ella no es el hombre, sino el objeto para beber, sentarse, vestirse o dormir.

\section{Dialéctica General del Arte}

En el arte se encuentra una de las más importantes manifestaciones objetivas de la fuerza revolucionaria del hombre en la realidad. La misma fuerza que hace agradable al mundo, al hacer irrumpir en él la belleza, es la fuerza de la creación artística.

Solo el hombre hace arte, solo él es capaz de ir más allá de su inmediatez natural y transformar a su voluntad el entorno. Esta es la razón por la cual el artista no se pierde detrás de su obra, sino que plasma en ella las particularidades de su genio, al mismo tiempo que plasma la fuerza del género humano configurada en sensibilidad estética. El hombre, particular y genérico, constituye el más profundo contenido de cada obra de arte bello. Cada manifestación de las bellas artes contiene, junto al genio maduro de la imaginación creadora del artista, la fuerza vital con la que la humanidad construye su mundo y lo revoluciona, pues la misma fuerza que permite al hombre transformar la realidad, mueve al artista a crear. 
La imaginación creadora abre la posibilidad de intuir y materializar lo bello. Es solo en ella donde podemos encontrar el origen del proyecto o idealidad ${ }^{\dagger}$ de la obra. Es también en ella donde se inicia esa experiencia vital de quién crea, y dónde el creador alcanza su propia satisfacción, solo cuando su obra está terminada. Bien escribió Hegel: “...se trata solo de una necesidad insatisfecha, y presente en el sujeto como algo insuficiente que se esfuerza por superar y alcanzar la satisfacción" (Hegel, 1983, t. 5:21).

La imaginación creadora engendra en el artista la emoción de crear. Emoción que es a la vez muy suya y muy general a toda la humanidad. La emoción artística es una sensación de poder en mis manos que me precipita a la creación. Toda aproximación a lo artístico implica, de modo indirecto, una exposición del hombre ante sí mismo, pues tiene así la necesidad de una antropología filosófica dentro de su acervo conceptual.

En el arte se encuentran, en un justo equilibrio, la subjetividad y la objetividad del hombre particular y el genérico. Es esta la razón por la

9. Hegel pensaba que la idealidad en el arte era la formulación y configuración por parte del espíritu, Ibidem, tomo 2, p. 122. cual, en el objeto artístico, se puede reconocer al artista y su época, justo al lado de la humanidad y su fuerza. La historicidad de un objeto de arte no se encuentra en su temática, sino en su estética.

\section{El origen del arte}

El arte surgió de la actividad del hombre sobre su realidad como parte y medio de su dominio sobre la naturaleza, que ante él, se levantaba como desconocida y amenazante. Solo allí, en el esfuerzo por dominar, la inteligencia humana pudo asignar al arte la función de embellecer su mundo. Solo allí, en el momento en el que la realidad no era aun un mundo, la inteligencia humana tuvo que esforzarse al máximo en copiar, del modo más perfecto, lo real. El arte más primitivo es aquel que más pretende acercarse, $\mathrm{o}$ copiar, a la realidad

En la aparición del arte la voluntad ordenadora del hombre sobre la realidad se representó como objetividad mágica que alienaba al hombre de sus propias capacidades. Es solo la incapacidad de la racionalidad humana para comprender, desde su primer momento, que en sus manos se encontraba el poder para convertir lo real en su hogar, y el origen de su ser hombre, lo que llevó a que las primeras manifestacio- 
nes del arte fueran de carácter mágico-religioso.

El arte fue el primer instrumento de creación de un cierto tipo de conocimiento que un intelecto en ciernes, incapaz de encontrarse a sí mismo, pudo engendrar. En sus albores, el hombre no tiene plena conciencia de su poder sobre la realidad, sino que la transforma bajo la pureza del instinto, y no ve en sí mismo el poder del ordenamiento, sino que, fruto de esa ignorancia, lo coloca por encima de él.

En su origen más íntimo, el arte expresa la religiosidad propia de una racionalidad primitiva, apquella en la que se simboliza un más allá, sin darse cuenta de que detrás de ello solo se encuentra su inexistencia.

El mismo motivo que lleva al hombre a crear a Dios, lo lleva a crear el arte. Se trata de la pesada contradicción irresoluble entre vivir una vida sin sentido, y la necesidad de alcanzar un sentido para su ser. Esto le origina al hombre multidimensional una inconformidad fundamental con su situación, y lo obliga a crear el mundo, el arte, la religión y la filosofía, todos ellos como formas por las cuales pretende convertir su existencia en vida, arrojando claridad en esta oscuridad.
La inconformidad con su situación, su realidad, es el origen de la fuerza revolucionaria de la humanidad a la que tanto he aludido. Esta fuerza consiste en la capacidad de transformar la naturaleza en el mundo que habitamos. Esta es la fuerza humana de la inconformidad, la que se particulariza en el artista como deseo de crear, y es a través de ella, que el artista juega con la ontología del mundo, el ser del hombre, y la epistemología de la técnica. En el arte estamos ante un juego, posible ante todo, porque el hombre se despliega sobre la realidad como acción, y la transforma mediante la negación de lo existente. ¿Qué es el hombre sino un ser revolucionario cuya complejidad intestina lo lleva a estar siempre inconforme con lo que posee?

Creo firmemente que todos transformamos nuestra realidad, pero no todos tienen la capacidad de representar, en un objeto, la sensibilidad que de tal actividad surge. Todos deberíamos ser artistas o filósofos, pero lo cierto es que la mayoría tan solo llega a ser mediocre e ignorante.

\section{La subjetividad creadora}

La subjetividad del artista es su imaginación. Ella posibilita materializar la sensibilidad estética de 
una época. El artista es un humanista práctico. Su subjetividad creadora hace imagen el acto por el que la realidad se transforma en un sitio agradable. La imaginación creadora del artista juega libre con la técnica, y con las cualidades de los materiales que posee frente a sí.

Como individuo, el artista enfrenta el mundo y su existencia mediado socialmente por una sensibilidad estética que, o bien recoge, o bien crea, para exponerla. La creación artística da un exclusivo placer: el regocijarse en su propia creatividad. Este éxtasis del hacer, lleva al artista de genio a encerrarse en sí mismo, al punto de ser lo que está haciendo. $\mathrm{El}$ artista crea por el placer de hacerlo, lo cual es posible porque vive en su acción la fuerza vital del género humano.

Por desgracia, la herencia que la estética fetichista deja al arte consiste en la desaparición de la posibilidad de comunicar, en forma clara, su contenido, tanto el que el artista deseaba expresar a su público, como el que la estética de la obra encierra. Reducir a mercancía el arte eliminó la capacidad, que poseía tiempo atrás, de ser medio de comunicación para sus contenidos. El artista se ve obligado por ello a explicar su obra, a hacer discurso estético, y por tanto filosofía. Pero, en no pocos ca- sos, cuando lo intenta, fracasa. Ante esto, lo que puede superar el trance de la incomunicabilidad, es que, el objeto constituya, a la sensibilidad estética que materializa, en una región de encuentro entre el artista, el público y el mundo, es decir, que el artista no pretenda nada más que materializar la belleza. La historia ha colocado a la filosofía en posición de extraer del arte su intención, denunciando al hombre ante sí mismo, que es, a la vez, denunciar la fealdad del mundo capitalista.

El valor humanista que debe proponérsele al arte de hoy consiste en permitir ir más allá de este mundo sin salirse de él llenándolo con belleza, a modo de lo que Nietzsche propusiera "alienar sin hacer daño", haciendo, entonces, agradable la vida. En el arte el mundo puede aparecer transformado en un nuevo mundo. Esto solo lo puede hacer el artista de genio, y por ello la obra nunca puede ir más allá de su autor. En su creación el artista retoma el protagonismo del hombre sobre la realidad, se enseñorea, no solo con respecto a su obra, sino también con respecto al mundo. El arte es patrimonio común de la humanidad; por ello su temática no puede ser otra más que el hombre y las cosas de su mundo, sin fronteras, un todo expuesto ante el artista a modo de 
aquel "museo imaginario" que Durand nos propone acertadamente en su obra. ${ }^{10}$

Toda filosofía del arte, y toda estética de la belleza, requiere unificar en un único discurso una ontología que permita comprender al objeto de arte en relación con el mundo, a su vez una epistemología que permita comprender la constitución de corrientes y sensibilidades estéticas, así como de técnicas instrumentales para el arte. Y finalmente una antropología que rescate el valor más profundo del arte en la actividad general del hombre.

\section{BIBLIOGRAFIA}

Adorno, Teodoro, (1980) Teoría estética, Taurus, Madrid, España.

BozAl, V., Historia de las ideas estéticas y teorías estéticas contemporáneas, La Balsa de medusa, Madrid, España, 1996.

BRETóN, André, (1969) Manifiestos del Surrealismo, Guadarrama, España.

BüRGER, Roger, (1999) Crítica de la estética idealista, La Balsa de la medusa, Madrid, España.

GeORG F. W. Hegel, (1983) Estética, traductor E. Llanos, Siglo Veinte, Argentina.

GILBERD DuRAND, (1982) La Imaginación Simbólica, Taurus, España.

KANT, Emmanuel, (1997) Crítica del juicio, traduce. García Morente, Austral, España.

10. Op. Cit., "La Imaginación Simbólica”. 